\title{
Environmental Enrichment, Age, and PPAR $\alpha$ Interact to Regulate Proliferation in Neurogenic Niches
}

\author{
Margarita Pérez-Martín ${ }^{1 \dagger}$, Patricia Rivera ${ }^{2 \dagger}$, Eduardo Blanco ${ }^{2,3 \dagger}$, Clara Lorefice ${ }^{1,2}$, \\ Juan Decara ${ }^{2}$, Francisco J. Pavón ${ }^{2}$, Antonia Serrano ${ }^{2}$, Fernando Rodríguez de Fonseca ${ }^{2}$ \\ and Juan Suárez ${ }^{2 *}$ \\ ${ }^{1}$ Departamento de Biología Celular, Genética y Fisiología, Instituto de Investigación Biomédica de Málaga, Universidad de \\ Málaga, Málaga, Spain, ${ }^{2}$ UGC Salud Mental, Instituto de Investigación Biomédica de Málaga, Universidad de \\ Málaga-Hospital Universitario Regional de Málaga, Málaga, Spain, ${ }^{3}$ Departament de Pedagogia i Psicologia, Facultat \\ d'Educació, Psicologia i Treball Social, Universitat de Lleida, Lleida, Spain
}

OPEN ACCESS

Edited by:

José Luis Trejo,

Cajal Institute-CSIC, Spain

Reviewed by:

Francis G. Szele,

University of Oxford, UK

Djoher Nora Abrous,

Institut des Neurosciences de

Bordeaux, France

María Llorens-Martín,

Consejo Superior de Investigaciones

Científicas, Spain

*Correspondence:

Juan Suárez

juan.suarez@ibima.eu;

fernando.rodriguez@ibima.eu

${ }^{\dagger}$ First co-authors.

Specialty section:

This article was submitted to

Neurogenesis,

a section of the journal

Frontiers in Neuroscience

Received: 10 November 2015

Accepted: 22 February 2016

Published: 09 March 2016

Citation:

Pérez-Martín M, Rivera P, Blanco E, Lorefice C, Decara J, Pavón FJ,

Serrano A, Rodríguez de Fonseca $F$

and Suárez J (2016) Environmental

Enrichment, Age, and PPAR $\alpha$ Interact

to Regulate Proliferation in Neurogenic

Niches. Front. Neurosci. 10:89.

doi: 10.3389/fnins.2016.00089
Peroxisome proliferator-activated receptor alpha (PPAR $\alpha$ ) ligands have been shown to modulate recovery after brain insults such as ischemia and irradiation by enhancing neurogenesis. In the present study, we investigated the effect of the genetic deletion of PPAR $\alpha$ receptors on the proliferative rate of neural precursor cells (NPC) in the adult brain. The study was performed in aged Ppar ${ }^{-1-}$ mice exposed to nutritional (treats) and environmental (games) enrichments for 20 days. We performed immunohistochemical analyses of cells containing the replicating cell DNA marker 5-bromo-2'-deoxyuridine $(\mathrm{BrdU}+)$ and the immature neuronal marker doublecortin $(\mathrm{Dcx}+)$ in the main neurogenic zones of the adult brain: subgranular zone of dentate gyrus (SGZ), subventricular zone of lateral ventricles (SVZ), and/or hypothalamus. Results indicated a reduction in the number of BrdU+ cells in the neurogenic zones analyzed as well as Dcx+ cells in the SGZ during aging (2, 6, and 18 months). Ppar $\alpha$ deficiency alleviated the age-related reduction of NPC proliferation (BrdU+ cells) in the SVZ of the 18-months-old mice. While no genotype effect on NPC proliferation was detected in the SGZ during aging, an accentuated reduction in the number of Dcx+ cells was observed in the SGZ of the 6-months-old Ppar ${ }^{-1-}$ mice. Exposing the 18-months-old mice to nutritional and environmental enrichments reversed the Ppar $\alpha^{-1-}$-induced impairment of NPC proliferation in the neurogenic zones analyzed. The enriched environment did not modify the number of SGZ DCX + cells in the 18 months old Ppar $\alpha^{-/}$mice. These results identify PPAR $\alpha$ receptors as a potential target to counteract the naturally observed decline in adult NPC proliferation associated with aging and impoverished environments.

Keywords: aging, environment, $\operatorname{PPAR} \alpha$, subventricular zone, hippocampus, neurogenesis

Abbreviations: 3v, third ventricle; ARC, arcuate nucleus of hypothalamus; BrdU, 5-bromo-2'-deoxyuridine; Dcx, doublecortin; EE, enriched environment; gcl, granular cell layer; lv, lateral ventricle; ml, molecular layer; NPC, neural proliferative cells; pcl, polymorphic cell layer; $\mathrm{Ppar}^{-/-}$, homozygous knockout in peroxisome proliferator-activated receptor alpha; SE, standard environment; SGZ, subgranular zone of dentate gyrus; Str, striatum; SVZ, subventricular zone of the lateral ventricles; $\mathrm{VMH}$, ventromedial nucleus of hypothalamus; WT, wild-type. 


\section{INTRODUCTION}

Neural progenitor/proliferative cells (NPC) are derived from embryonic radial-glial cells that have the ability to divide, selfrenew and generate functional differentiated cells (neurons and glia) during the entire life of the animal (Doetsch, 2003b). NPC are localized in discrete regions of the adult mammalian brain called stem cells niches, such as the subventricular zone (SVZ) lining the walls of the lateral ventricles and the subgranular zone (SGZ) of the hippocampal dentate gyrus, which are capable of promoting neurogenesis and gliogenesis (Doetsch et al., 1999; Doetsch, 2003a; Lie et al., 2004; Albayram et al., 2011). In the last decade, several studies evidenced the hypothalamus as a novel neurogenic zone in the adult brain, especially after insults (Rivera et al., 2011; Robins et al., 2013; Maggi et al., 2014; Lin and Iacovitti, 2015; Lin et al., 2015).

It is well-known that NPC proliferation and neuronal differentiation are regulated by intrinsic (growth factors, neurotransmitters, hormones) and external (environment, caloric intake, drugs) factors, as well as by epigenetic mechanisms that intermediate in between the environment and the genome (Alvarez-Buylla and Lim, 2004; Arias-Carrion et al., 2007; Montalban-Loro et al., 2015). A critical factor affecting the rate of adult neurogenesis is age (Drapeau et al., 2003; Aizawa et al., 2009; Coras et al., 2010; Ngwenya et al., 2015). In adult rodents, hippocampal neurogenesis persists throughout the lifespan but suffers from progressive age-associated declines (Kuhn et al., 1996; McDonald and Wojtowicz, 2005). This fact is relevant since aging is also associated with an increased risk for cerebral insults, even in healthy subjects. Multiple studies have linked the age-induced decline of NPC and neurogenesis with neurodegenerative diseases and cognitive performance (Van Praag et al., 2005; Paillard, 2015). However, others reports have suggested that such a relationship does not exist (Bizon and Gallagher, 2003; Merrill et al., 2003). Several factors have a positive influence on cerebral decline associated with normal aging. In this line, environmental enrichment, including nutrition and physical activity, may improve brain function in normal animals and in animals with brain-related disorders, such as Alzheimer and other aging-related cerebral diseases, which, in part, are likely mediated through the enhancement of neurogenesis (Fan et al., 2007; Zhao et al., 2015; Garthe et al., 2016).

Peroxisome proliferator-activated receptors (PPARs) belong to a nuclear receptor superfamily capable of regulating physiological responses associated with inflammatory responses, energy metabolism, and cell proliferation, differentiation, migration and survival (Rosen and Spiegelman, 2001; Smith et al., 2003; Fidaleo et al., 2014). It has been reported that PPAR $\alpha$ and its endogenous ligands (eicosanoids, leukotrienes, and endocannabinoid-like molecules such as oleoylethanolamide or OEA) support a role in neuroprotection against oxidative stress, which is target for neurodegenerative diseases and contribute to normal brain aging (Nunomura et al., 2012; Zolezzi et al., 2013; Fidaleo et al., 2014). PPAR $\alpha$ is expressed in neuronal, astroglial, and ependymal cells and may be relevant in glutamatergic, dopaminergic, and cholinergic neurotransmission (Zhou and
Waxman, 1998; Avshalumov and Rice, 2002; Melis et al., 2013). For instance, PPAR $\alpha$ activity modulates acetylcholine release and ameliorates cognitive and memory decline associated with aging (Hajjar et al., 2012). OEA-PPAR $\alpha$ interaction facilitates memory consolidation through noradrenergic activity (Campolongo et al., 2009), modulates satiety responses through hypothalamic neurons (Romano et al., 2013), and regulates motivational responses for alcohol through the peripheral nervous system (Bilbao et al., 2015). Interestingly, the involvement of PPAR $\alpha$ in cell proliferation and apoptosis (Roberts et al., 2002; Cimini et al., 2007; Cimini and Ceru, 2008) as well as neural cell differentiation and maturation has been demonstrated (Cristiano et al., 2005; Bento-Abreu et al., 2007; Fandel et al., 2013). PPAR $\alpha$ activation (for instance, through the elevation of the PPAR $\alpha$ endogenous ligands in the brain) preserves hippocampal neurogenesis and inhibits microglial activity (Ramanan et al., 2009; Rivera et al., 2015a).

Although, PPAR $\alpha$ may be a potential therapeutic target in neurodegenerative, neuroinflammatory and neurocognitive alterations related to Alzheimer and Parkinson's diseases (PlazaZabala et al., 2010; Scuderi et al., 2012; Fidaleo et al., 2014; González-Aparicio et al., 2014), the involvement of PPAR $\alpha$ in age-related decline and environmental enrichment-induced enhancement of adult neurogenesis is still uncertain. The present study designed an experimental approach to investigate the potential role of PPAR $\alpha$ in adult NPC proliferation by focusing on the impact of sustained external stimulation through food and play. Immunohistochemistry were performed to analyze cells that contained the replicating cell DNA marker 5-bromo$2^{\prime}$-deoxyuridine $(\mathrm{BrdU}+)$ in the main neurogenic zones (SVZ, SGZ, and hypothalamus), as well as cells expressing the immature neuronal factor doublecortin (Dcx+) in the SGZ. This study was performed in adult aged mice lacking Ppara gene expression $\left(P_{p a r \alpha^{-l-}}\right)$ that were previously exposed to nutritional (treats) and environmental (games) enrichments for 20 days.

\section{MATERIALS AND METHODS}

\section{Ethics Statement}

The protocols and procedures were approved by the Ethics Committee of Malaga University (CEUMA: 2014-0001-A) and performed in compliance with European animal research laws [European Communities Council Directives2010/63/UE, 90/219/CEE, Regulation (EC) No 1946/2003] and Spanish National and Regional Guidelines for Animal Experimentation and Use of Genetically Modified Organisms (Real Decreto 53/2013, Ley 32/2007, and Ley 9/2003, Real Decreto 178/2004, Decreto 320/2010). All efforts were made to minimize animal suffering and reduce the number of animals used.

\section{Animals}

Adult wild-type (WT) and ppara $^{-/-}$(KO) male mice (The Jackson Laboratories, Bar Harbor, ME, USA) derived from intercrosses between heterozygous Ppara $^{+/-}$mice on a C57Bl/6 background were jointly housed in cages and maintained in standard conditions at $20 \pm 2^{\circ} \mathrm{C}$ room temperature with $40 \pm 5 \%$ relative humidity and a 12 -h light/dark cycle with a dawn/dusk 
effect (Animal House, University of Málaga). Standard rodent chow (Prolab RMH 2500, $2.9 \mathrm{kcal} / \mathrm{g}$ ) and water were available ad libitum.

\section{Aging}

The SVZ, SGZ and hypothalamus of the WT and Ppard ${ }^{-/-}$mice at ages of 2, 6, and 18 months old were analyzed. Six experimental groups were obtained depending on the age and genotype $(n=6$ mice per group): WT 2 months group, WT 6 months group, WT 18 months group, $P_{p a r \alpha}^{-/-}(\mathrm{KO}) 2$ months group, $P$ pard ${ }^{-/-}$

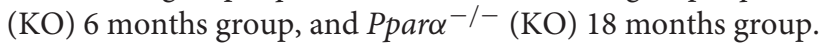

\section{Environmental Enrichment}

A new batch of WT and Ppar $\alpha^{-1-}$ mice at 18 months old $(n=$ 10 animals per genotype) were randomly selected to perform the environmental enrichment experiments. Thus, half of the mice from each genotype $(n=5)$ were housed in an enriched environment (EE) or standard environment (SE) cages for 20 days (Figure 1). We designed two EE configurations ( $a$ and $b$, see Figure 1A), which consisted of two large cages $(59.5 \times 38$ $\times 20 \mathrm{~cm}$ ) with different set of objects and games such as ramps, floor platforms, tunnels, and toys. WT and $P$ pard ${ }^{-/-}$mice were changed to $\mathrm{a}$ or $\mathrm{b}$ environmental configurations every 2 days, up to 20 days, to avoid habituation induced by prolonged contextual (spatial) stimulation. Nutritional enrichment was also performed by adding different treats such as fruits, crackers, and cheese in cycles of 6 days for 20 days (Figure 1B). The control WT and $\mathrm{Ppar \alpha}^{-1-}$ mice were housed in standard environment cages (equal cage dimension but no objects inside) and fed with the standard chow but without nutritional enrichment (treats). Four experimental groups were obtained depending on the genotype and environment ( $n=5$ mice per group): WT SE group, WT EE group, Ppard $^{-/-}$(KO) SE group, and $P$ par ${ }^{-/-}$(KO) EE group.

\section{BrdU Administration}

5'-bromo-2'-deoxyuridine (BrdU, cat. no. B5002, Sigma, St. Louis, MO, USA) was dissolved at $15 \mathrm{mg} / \mathrm{mL}$ in sterile $0.9 \%$ $\mathrm{NaCl}$ solution. BrdU was i.p. administered at a dose of $50 \mathrm{mg} / \mathrm{kg}$ body weight once per day for 3 consecutive days (day 17-19) and twice at the last EE-day (day 20, $4 \mathrm{~h}$ between injections). The animals were killed $12 \mathrm{~h}$ after the last injection of BrdU was administered.

\section{Brain Collection}

All animals were intraperitoneally (i.p.) anesthetized (sodium pentobarbital, $50 \mathrm{mg} / \mathrm{kg}$ body weight) and transcardially perfused

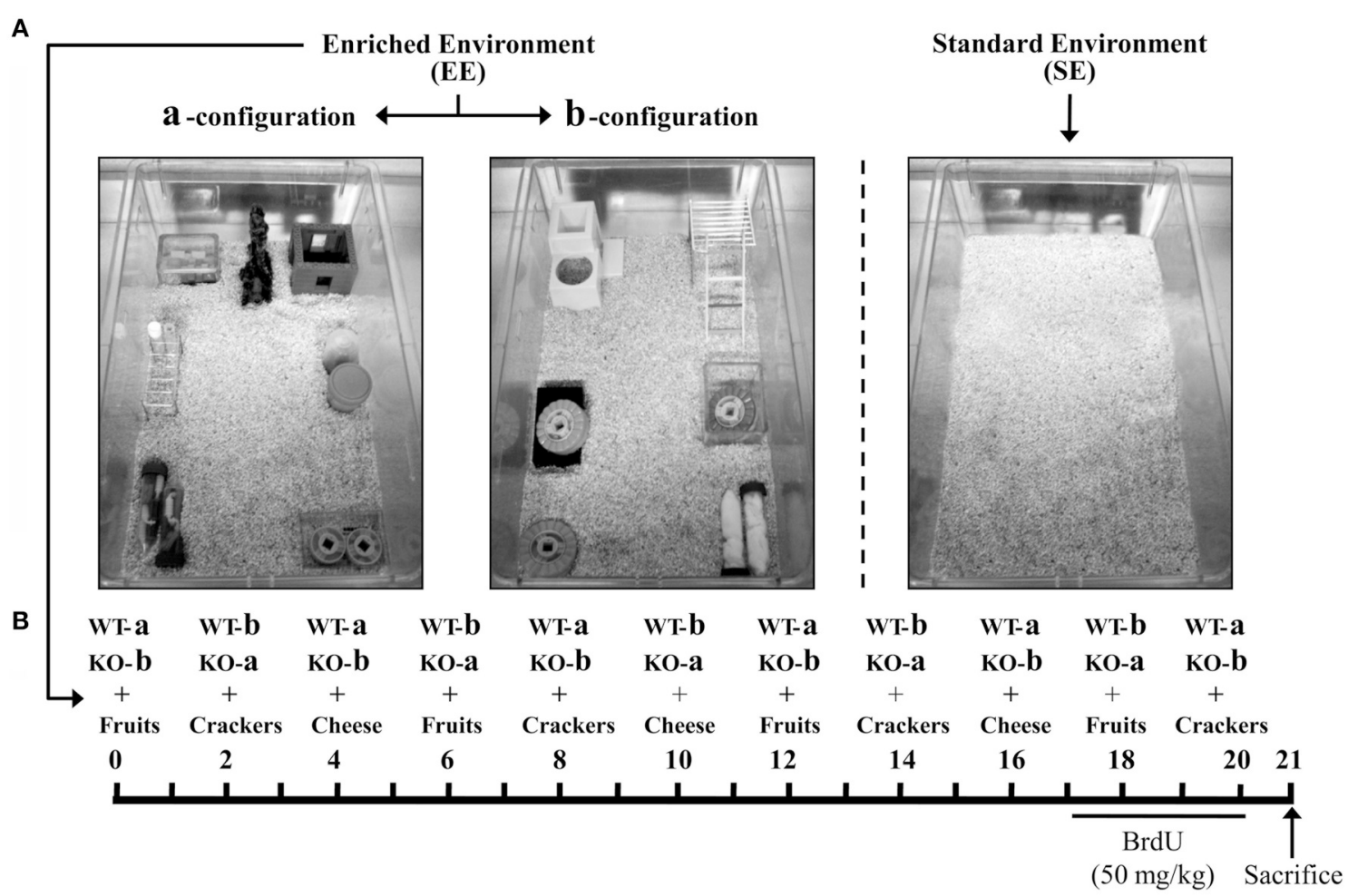

FIGURE 1 | (A) Housing conditions of the wild-type (WT) and Ppara ${ }^{-/-}(\mathrm{KO})$ mice. The photographs illustrated the different set of environmental configurations: two enriched environmental configurations ( $\mathrm{a}$ and $\mathrm{b}$ ) consisting of a contextual stimulation with ramps, floor platforms, tunnels and toys, and a standard environment (a standard housing cage). (B) Schematic diagram showing the experiment design. The mice from each genotype were randomly assigned to the standard environment (SE) or the nutritional and environmental enrichment (EE) for 20 days. The mice rotated between the enriched configurations a and b every 2 days. Nutritional enrichment consisted of the administration of different treats such as fruits, crackers, and cheese in cycles of 6 days. The last 4 days previous to sacrifice, all animals were injected with BrdU $(50 \mathrm{mg} / \mathrm{kg})$. 
with $4 \%$ formaldehyde in $0.1 \mathrm{M}$ phosphate buffer (PB). The brains were dissected out and kept in the same fixative solution overnight at $4{ }^{\circ} \mathrm{C}$. The brains were then cryoprotected and cut into $30-\mu \mathrm{m}$-thick coronal sections by using a sliding microtome (Leica VT1000S). Sections were divided in eight parallel series until use for immunohistochemistry.

\section{Immunohistochemistry}

Free-floating coronal sections from -1.58 to $-2.46 \mathrm{~mm}$ Bregma levels (hippocampus and hypothalamus) and 1.42 to $-0.10 \mathrm{~mm}$ Bregma levels (striatum) from one of the five parallel series obtained from each mouse brain were selected for each immunohistochemistry (Paxinos and Franklin, 2004). Sections were first washed several times with PBS to remove sodium azide. Then, sections were incubated in a solution of $3 \%$ hydrogen peroxide and $10 \%$ methanol in $\mathrm{PB} 0.1 \mathrm{M}$ for $45 \mathrm{~min}$ at room temperature in darkness to inactivate endogenous peroxidase. After three washes in PBS for $10 \mathrm{~min}$, DNA was denatured by exposing sections to $\mathrm{HCl} 2 \mathrm{~N}$ for $15 \mathrm{~min}$ at $37^{\circ} \mathrm{C}$, followed by two washes in borate buffer $0.15 \mathrm{M}$ to neutralize $\mathrm{pH}$. After three additional washes in PBS for $10 \mathrm{~min}$, sections were incubated in a blocking solution containing $0.3 \%$ albumin, $0.3 \%$ triton X-100 and $0.05 \%$ sodium azide in PBS for $45 \mathrm{~min}$. Sections were incubated overnight in the primary antibody rat anti-BrdU (1:500; Accurate Chemical \& Scientific, Westbury, NY, USA, cat. no. OBT0030G) at $4^{\circ} \mathrm{C}$. For doublecortin immunohistochemistry, selected sections at hippocampal levels were firstly incubated in a solution of $3 \%$ hydrogen peroxide and $10 \%$ methanol in PB $0.1 \mathrm{M}$ for $10 \mathrm{~min}$, secondly incubated in a blocking solution containing $5 \%$ horse serum, $0.3 \%$ triton X-100 and $0.05 \%$ sodium azide in PBS for $1 \mathrm{~h}$, and finally incubated overnight in the primary antibody goat anti-doublecortin (1:500; Santa Cruz Biotechnology, cat. no. sc-8066) at room temperature. The following day the sections were incubated in the biotinylated donkey anti-rat IgG $(\mathrm{H}+\mathrm{L})$ antibody (1:500, Novex; cat. no. A18743) or the biotinylated horse anti-goat IgG antibody (1:1000, Vector; cat. no. BA-9500) for $90 \mathrm{~min}$. The sections were then incubated in ExtrAvidin peroxidase (Sigma, St. Louis, MO) diluted 1:2000 in darkness at room temperature for $1 \mathrm{~h}$. Finally, immunolabeling was revealed with $0.05 \%$ diaminobenzidine (DAB; Sigma) and $0.03 \% \mathrm{H}_{2} \mathrm{O}_{2}$ in PBS.

\section{Quantification of BrdU and Doublecortin-Immunoreactive Cells}

The average density of positive cells per animal was quantified. Thus, the estimation of the number of cells per section $(30 \mu \mathrm{m}$ deep) and area $\left(\mathrm{mm}^{2}\right)$ in both hemispheres was calculated according to the following formula: $\mathrm{Na}=\sum(Q-) / \sum\left(a_{\text {str }}\right)$, where $\sum Q$ - is the total number of positive cells counted per animal and $a_{\text {str }}$ is the area of the structure analyzed. Each structure analyzed consisted of $\sim 6$ coronal sections, which resulted in one of every five equidistant sections (one representative section for each $180 \mu \mathrm{m}$ ) according to the rostro-caudal extent. To outline the area of study, the region of interest was drawn in each structure, whose identification was performed at Bregma -1.58 to $-2.46 \mathrm{~mm}$ in hippocampal and hypothalamic levels, and at Bregma 1.42 to $-0.10 \mathrm{~mm}$ in striatal levels according to a mouse brain atlas and cytoarchitectonic criteria (Paxinos and Franklin, 2004). Thus, the BrdU-immunoreactive (-ir) nuclei and doublecortin-ir cells that came into focus were manually counted in the subgranular zone (SGZ) of the dentate gyrus and/or the subventricular zone (SVZ) of the lateral ventricles. Regarding the hypothalamus, counting was performed in the ventromedial (VMH) and arcuate (ARC) nuclei of the hypothalamus and median eminence. Quantification were performed using a standard optical microscope with the 40X objective (Nikon Instruments Europe B.V., Amstelveen, The Netherlands) coupled to the NIS-Elements Imaging Software 3.00 (Nikon). The data were expressed as the number of positive cells per area $\left(\mathrm{mm}^{2}\right)$.

\section{Statistical Analysis}

Statistical analysis of the results was performed using the computer program GraphPad Prism version 5.04 (GraphPad Software Inc., San Diego, CA, USA). Data were represented as the mean \pm s.e.m. for five-six determinations depending on the experimental group. Statistical analysis was performed using twoway ANOVA followed by Bonferroni post hoc test for multiple comparisons. $P<0.05$ was considered to be significant.

\section{RESULTS}

\section{Effect of Age and Genotype on SVZ, SGZ, and Hypothalamic Cell Proliferation}

Typical clustering of newborn cells containing nuclear BrdU labeling was observed in the SVZ of the lateral ventricles extending from the ventral to the dorsolateral ventricular peak and into the rostral migratory stream following a transversal view of the adult mouse brain (Figure 2). This arrangement of the SVZ $\mathrm{BrdU}+$ cells was more evident in the younger mice that the older ones. Scattered BrdU + cells were found in the SGZ of the dentate gyrus as well as in a hypothalamic area, by the wall of the third ventricle, including the hypothalamic ventromedial and arcuate nuclei, and the median eminence. Qualitatively, we observed a less number of cells containing BrdU in the three neurogenic niches during the ages analyzed (Figure 2).

Two-way ANOVA showed an age effect (2, 6, and 18 months) on the three neurogenic areas [SVZ: $F_{(2,19)}=12.98 ; P<0.001$; SGZ: $F_{(2,19)}=41.73, P<0.001$; hypothalamus: $F_{(2,19)}=5.51$; $P<0.05$; Figure 2]. Interestingly, a genotype effect (WT and $\mathrm{KO}$ ) was found in the number of BrdU+ cells in the SVZ $\left[F_{(1,19)}=6.45, P<0.05\right]$, but not in the SGZ or hypothalamus. No interaction between age and genotype was detected, that is, PPAR $\alpha$ deficiency did not produce a different effect on cell proliferation during aging.

After performing the Bonferroni analysis, we found a decreased number of BrdU+ cells in the SVZ of the lateral ventricles of the 18 months old WT mice compared to that of the 2 and 6 months old WT mice ${ }^{* * \# \#} P<0.01$; (Figures $2 \mathrm{~A}, \mathbf{D}-\mathbf{F}$ ). The number of BrdU+ cells was lower in the SVZ of the 18 months old KO mice than that of the 6 months old KO mice $\left({ }^{\$} P<0.05\right)$, but in increased compared to those of the 18 months old WT mice ( ${ }^{\circledR} P<0.05$; (Figures $\left.2 \mathrm{~A}, \mathbf{F}-\mathrm{I}\right)$. In the SGZ of the dentate gyrus, the number of BrdU+ cells decreased in the 6 and 18 months old WT mice ${ }^{* * *} P<0.01$ and ${ }^{* * *} P<0.001$, 

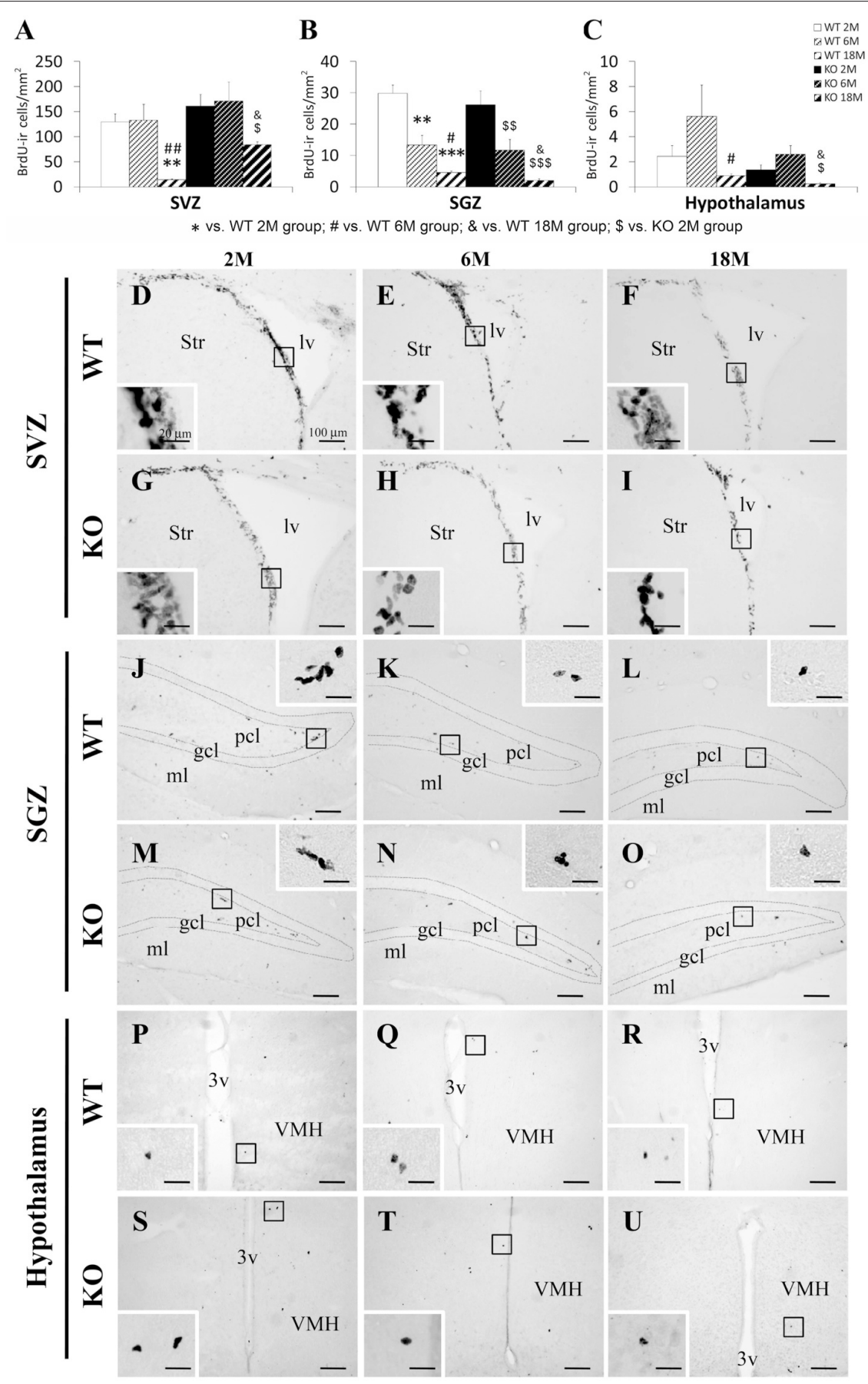

FIGURE 2 | Effect of age (2, 6, and 18 months) on the number of cells that contained BrdU in the SVZ (A), SGZ (B), and hypothalamus (C) of WT and Ppar $\mathbf{C}^{-1-}$ (KO) mice. The data were expressed as the media of the number of BrdU+ cells per area $\left(\mathrm{mm}^{2}\right)+$ s.e.m $(N=6)$. Bonferroni's test: ${ }^{\star *} P<0.01$, ${ }^{* \star *} p<0.001$ vs. WT $2 \mathrm{M}$ group; $\# P<0.05$, \#\#P<0.01 vs. WT $6 \mathrm{M}$ group; $\&_{P}<0.05$ vs. WT $18 \mathrm{M}$ group; $\$ P<0.05, \$ \$ P<0.01, \$ \$ \$ P<0.001$ vs. KO $2 \mathrm{M}$ group. (D-U) Representative photomicrographs showing low and high (insets) magnification views of the typical clustering of newborn cells containing the BrdU labeling in the SGZ, SVZ, and hypothalamus of 2, 6, and 18 months old WT and KO mice. Scale bars (100 $\mu \mathrm{m}$ and $20 \mu \mathrm{m}$ for insets) are included in each image.

respectively) and the 6 and 18 months old KO mice $\left({ }^{\$} P<0.01\right.$ and ${ }^{\$ \$ P} P<0.001$, respectively) compared to the respective 2 months old WT and KO mice (Figures 2 $\mathbf{B}, \mathbf{J}-\mathbf{O}$ ). The number of BrdU+ cells in the SGZ of the 18 months old WT mice was also decreased when it was compared to that of the 6 months old WT mice ( ${ }^{\#} P<0.05$; Figures $2 \mathbf{B}, \mathbf{K}, \mathbf{L}$ ). The number of BrdU+ cells in the SGZ of the 18 months old KO mice was decreased when it was compared to that of the 18 months old WT mice 
$\left({ }^{\&} P<0.05\right.$; Figures $\left.2 \mathrm{~B}, \mathbf{L}, \mathbf{O}\right)$. A decrease of BrdU+ cells was also found in the hypothalamus of the 18 months old WT and KO mice compared to the respective 6 months old WT and $\mathrm{KO}$ mice $\left({ }^{\$} P<0.05\right.$; Figures $\left.2 \mathrm{C}, \mathbf{Q}, \mathbf{R}, \mathbf{T}, \mathbf{U}\right)$. The number of BrdU+ cells in the hypothalamus of the 18 months old $\mathrm{KO}$ mice showed a decrease when it was compared to that of the 18 months old WT mice $\left({ }^{\&} P<0.05\right.$; Figures $\left.2 \mathrm{C}, \mathbf{R}, \mathbf{U}\right)$.

\section{Effect of Environmental Enrichment and Genotype on SVZ, SGZ, and Hypothalamic Cell Proliferation in 18 Months Old Mice}

Scattered clustering of newborn cells containing nuclear BrdU labeling was observed in the SVZ of the 18 months old mice (Figure 3). Qualitatively, this arrangement of the SVZ BrdU+ cells was more prominent in the mice lacking PPAR $\alpha$ receptors. The BrdU+ cells found in the SGZ and the hypothalamus of the older mice was very scarce. Qualitatively, we also observed a higher number of BrdU+ cells in the SGZ and the hypothalamus of the 18 months old mice exposed to the enriched environment (Figure 3).

Two-way ANOVA showed an environmental enrichment effect on the number of BrdU+ cells in the SGZ $\left[F_{(1,21)}=5.62\right.$; $P<0.05]$ and the hypothalamus $\left[F_{(1,21)}=7.2 ; P<0.05\right]$, but not in the SVZ (Figure 3). A genotype effect (WT and KO) on the number of BrdU+ cells was found in the SVZ $\left[F_{(1,21)}=48.34\right.$; $P<0.001]$ and the SGZ $\left[F_{(1,21)}=7.72 ; P<0.05\right]$, but not in the hypothalamus. Interaction between environmental enrichment and genotype was detected in SVZ cell proliferation $\left[F_{(1,21)}=7.47 ; P<0.05\right]$ and hypothalamic cell proliferation $\left[F_{(1,21)}=4.32 ; P<0.05\right]$, that is, PPAR $\alpha$ deficiency produced a different effect on SVZ and hypothalamic cell proliferation in an environment dependent-manner.

A Bonferroni analysis showed that the number of BrdU+ cells increased in the SVZ, but decreased in the SGZ and the hypothalamus of the $\mathrm{KO}$ mice compared to the WT ones when they were housed in a standard environment $\left({ }^{*} * * * * P<\right.$ 0.05/0.001; (Figures 3A-C,D,F,H,J,L,N). The number of BrdU+ cells was also increased in the SVZ of the KO mice compared to the WT ones when they were housed in an enriched environment for 20 days $\left({ }^{\$} P<0.01\right.$; (Figures 3A,E,G). The number of BrdU+ cells in the SVZ of the KO mice housed in an enriched environment decreased compared to those of the respective standard environment KO group ( ${ }^{\#} P<0.05$; (Figures 3A,F,G). In contrast, an increase in the number of BrdU+ cells was found in the SGZ of the WT and KO mice (Figures 3B,H-K) and the hypothalamus of the KO mice (Figures $\mathbf{3 C}, \mathbf{N}, \mathbf{O}$ ) housed in an enriched environment $\left({ }^{*}{ }^{\#} P<0.05\right)$.

\section{Effect of Age, Genotype, and Environmental Enrichment on SGZ Cells Expressing Doublecortin}

We analyzed the number of Dcx + cells in the SGZ of the WT and $\mathrm{KO}$ mice with 2, 6, and 18 months old, and with or without environmental enrichment (Figure 4). The presence of the Dcx+ cells in the SGZ was more evident in the younger mice that the older mice. Numerous cells expressing Dcx presented a cell body with a pyramidal shape and a main fiber that crossed the granular cell layer (Figures 4B,E).

Two-way ANOVA showed an age effect (2, 6, and 18 months) on the number of Dcx + cells $\left[F_{(2,12)}=10.27, P=0.0025\right]$. No genotype effect was observed, but interaction (age vs. genotype) was found when both 6 and 18 months old mice were only considered in the analysis $\left[F_{(2,8)}=6.03, P=\right.$ 0.0396]. This result suggested that PPAR $\alpha$ produced a different effect on the number of SGZ Dcx + cell from 6 months old onward in a genotype-dependent manner. Two-way ANOVA did not show an interaction and an environmental enrichment or genotype effect on the number of Dcx + cells in the SGZ of the 18-months-old mice, suggesting that PPAR $\alpha$ deficiency did not produce a different effect on the number of SGZ Dcx+ cells in an environment dependent-manner.

After performing the Bonferroni analysis, we found a decreased number of Dcx+ cells in the SGZ of the 6 and 18 months old WT mice compared to that of the 2 months old WT mice $\left({ }^{*} P<0.05\right)$ as well as a decreased number of Dcx + cells in the SGZ of the 18 months old WT mice compared to that of the 6 months old WT mice $\left({ }^{\#} P<0.05\right.$; Figures 4A-D). The number of Dcx + cells was also lower in the SGZ of the 6 and 18 months old $\mathrm{KO}$ mice than that of the 2 months old $\mathrm{KO}$ mice $\left({ }^{\$} P<0.01\right.$; (Figures $\left.4 \mathrm{~A}, \mathbf{E}-\mathbf{G}\right)$. Interestingly, the number of Dcx + cells decreased in the SGZ of the 6 months old $\mathrm{KO}$ mice compared to that of the respective 6 months old WT mice ( ${ }^{\$} P<0.05$; (Figures 4A,C,F). The Bonferroni analysis also indicated that the number of $\mathrm{Dcx}+$ cells increased in the SGZ of the 18 months old WT mice when they were housed in a enriched environment compared to the WT ones with standard environment $\left({ }^{*} P<0.05\right.$; (Figures $\left.4 \mathbf{H}, \mathbf{I}, \mathbf{J}\right)$ ). No change was observed in the 18 months old $\mathrm{KO}$ mice with enriched environment (Figures 4H,K,L).

\section{DISCUSSION}

In the present study we propose that $\operatorname{PPAR} \alpha$ may play a differential modulatory role in the maintenance of the adult cell proliferation depending on the neurogenic niche, the age and the environment under our experimental conditions. Our results are consistent with the well-known neurogenesis decline through the mouse lifespan (McDonald and Wojtowicz, 2005; Ngwenya et al., 2015). However, the absence of PPAR $\alpha$ alleviated the agerelated reduction of NPC proliferation (BrdU+ cells) in the SVZ of the 18 months old mice, while no genotype effect was detected regarding this fact in the SGZ and hypothalamus (Figure 5A). Interestingly, an accentuated reduction in the number of Dcx+ cells was observed in the SGZ of the 6 months old Ppara $\alpha^{-/-}$ mice. An enriched environment involving different contextual stimulation consisting of objects (ramps, floor platforms, tunnels, and toys) and treats (fruits, crackers, and cheese) for 20 days in aged mice lacking $\operatorname{PPAR} \alpha$ counteracted the accentuated decrease of NPC proliferation in the SGZ and the hypothalamus, and reestablished the cell proliferation reduction that was observed in the SVZ of older wild-type mice (Figure 5B). The enriched environment likely increased both cell proliferation and 


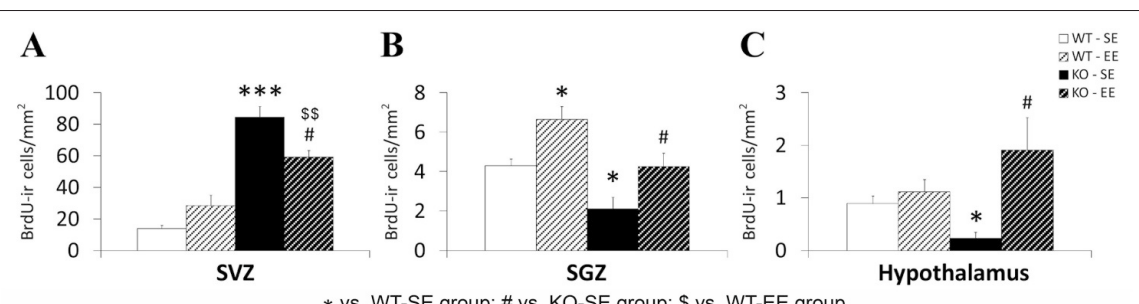

* vs. WT-SE group; \# vs. KO-SE group; \$ vs. WT-EE group

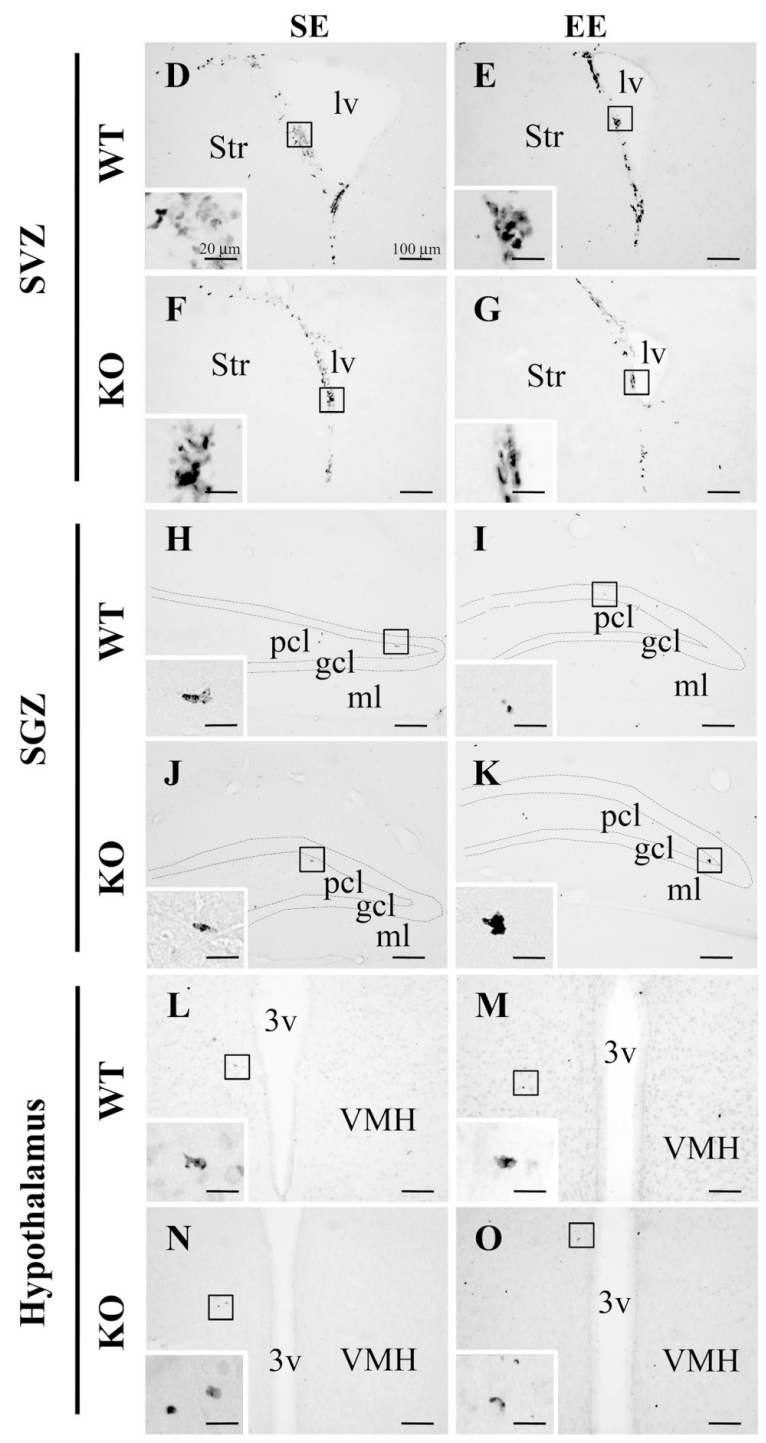

FIGURE 3 | Effect of environment (SE and EE) on the number of cells that contained BrdU in the SVZ (A), SGZ (B) and hypothalamus (C) of WT and Ppar $\alpha^{-l-}$ (KO) mice. The data were expressed as the media of the number of BrdU+ cells per area $\left(\mathrm{mm}^{2}\right)+$ s.e.m $(\mathrm{N}=5)$. Bonferroni's test: ${ }^{\star} P<0.05$, ${ }^{* *} P<0.001$ vs. WT-SE group; $\# P<0.05$ vs. KO-SE group; $\$ \$ P<0.01$ vs. WT-EE group. (D-O) Representative photomicrographs showing low and high (insets) magnification views of the typical clustering of newborn cells containing the BrdU labeling in the SGZ, SVZ and hypothalamus of WT or KO mice in a standard (SE) or enriched (EE) environment. Scale bars (100 and $20 \mu \mathrm{m}$ for insets) are included in each image.

maturation in the hippocampus of the 18 months old WT mice, as the number of BrdU+ cells and Dcx + cells was elevated in the SGZ. However, the enriched environment did not increase the very low number of the SGZ Dcx+ cells in the 18 months old Pparo $^{-1-}$ mice, as could be expected. In summary, the SGZ of the older $\mathrm{Ppard}^{-/-}$mice exposed to environmental enrichment showed an increase in cell proliferation but no change was found in the number of immature neurons expressing doublecortin. These results in the SGZ suggest an anticipation of the agedependent neurogenesis decline as a similar low number of 

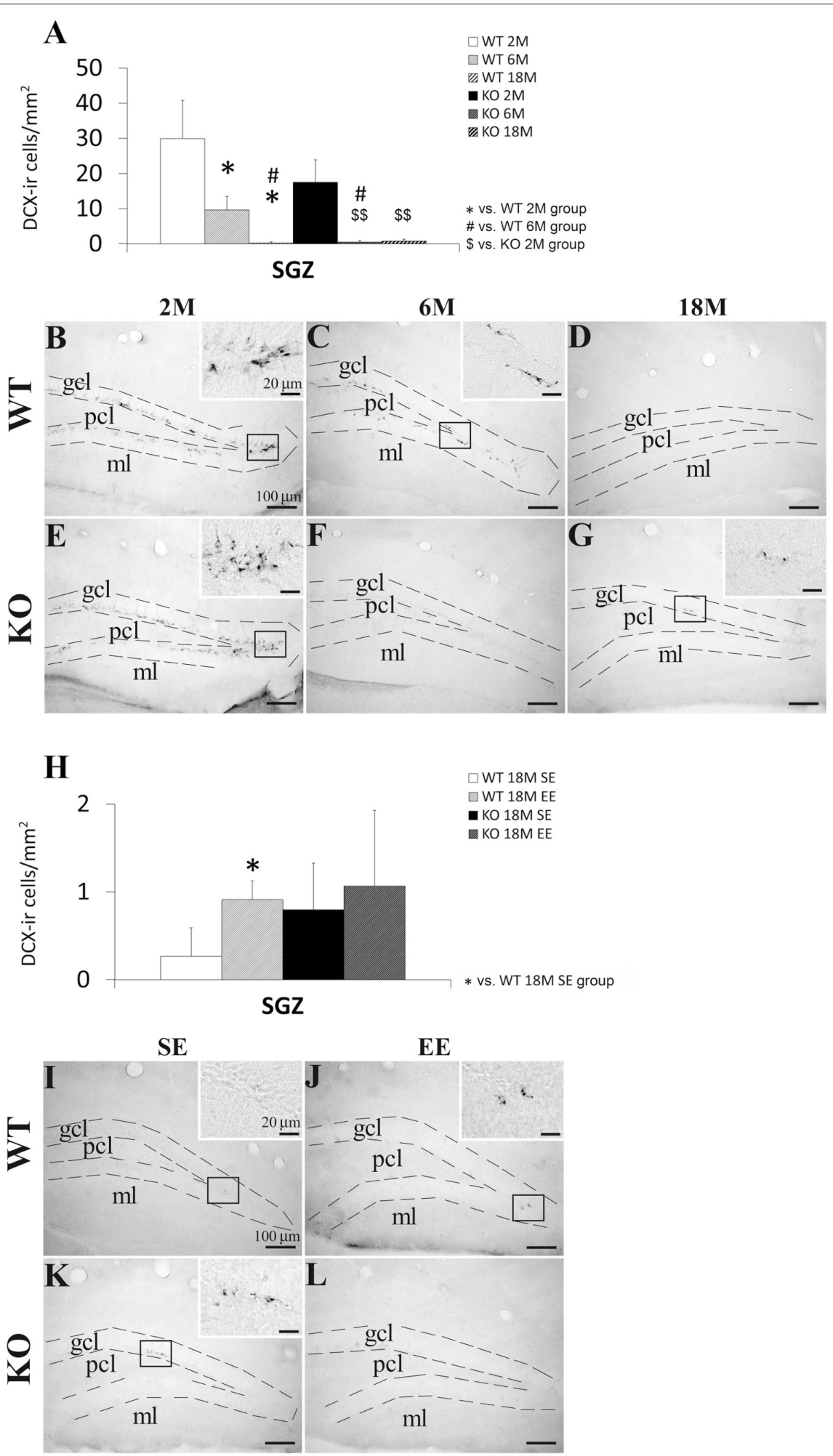

FIGURE 4 | Effect of age (2, 6, and 18 months) (A-G) and enriched environment (H-L) on the number of cells expressing doublecortin (Dcx) in the SGZ of WT and Ppara $\boldsymbol{C}^{-/-}$(KO) mice. The data were expressed as the media of the number of Dcx+ cells per area $\left(\mathrm{mm}^{2}\right)+$ s.e.m $(N=5)$. Bonferroni's test: ${ }^{*} P<0.05$ vs. WT $2 \mathrm{M}$ group or WT 18M SE group; $\# P<0.05$ vs. WT 6M group; $\$ P<0.01$ vs. KO $2 \mathrm{M}$ group. (B-G) Representative photomicrographs showing low and high (insets) magnification views of the Dcx+ cells in the SGZ of 2, 6, and 18 months old WT and KO mice. (I-L) Representative microphotographs showing low and high (insets) magnification views of the Dcx+ cells in the SGZ of 18 months old WT and KO mice in a standard (SE) or enriched (EE) environment. Scale bars (100 $\mu \mathrm{m}$ and $40 \mu \mathrm{m}$ for insets) are included in each image. 


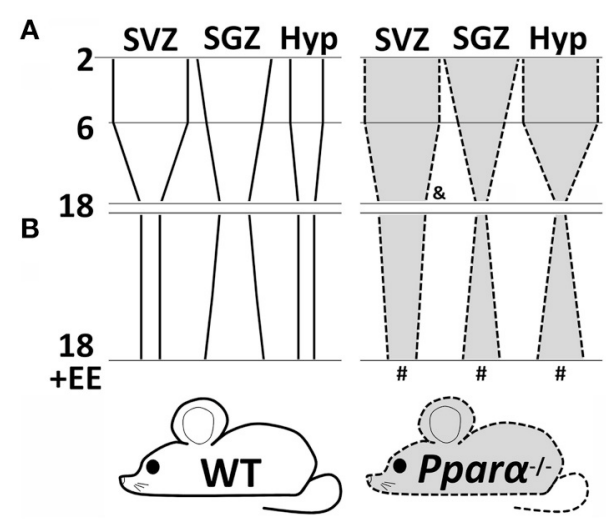

FIGURE 5 | A schematic diagram summarizing the changes of cell proliferation (BrdU+ cells) in the SVZ, SGZ and hypothalamus of wild-type (continuous lines and white background) and Ppar $\alpha$-/(dashed lines and gray background) mice during aging (A) and after an exposure to an nutritional and environmental enrichment for $\mathbf{2 0}$ days (B). Symbols indicate significant changes of cell proliferation between genotypes (WT vs. Ppara $\alpha^{-/-}$) in the 18 months old mice (\&) and between environments (SE vs. EE) in the 18 months old Ppar ${ }^{-/-}$mice (\#).

Dcx + cells was observed in the 6 and 18 months old Ppara ${ }^{-/-}$ mice compared to the progressive cell number decline in the respective wild-type mice. A putative impaired neurogenesis in the hippocampus of the older Ppara ${ }^{-/}$mice may be of great therapeutic relevance regarding the positive correlation between cognitive dysfunctions and hippocampal neurogenesis decline during aging (Drapeau et al., 2003; Aizawa et al., 2009; Coras et al., 2010). Further studies will be needed to elucidate the specific role of PPAR $\alpha$ signaling system (including endogenous activators, such as OEA, and their synthesizing and degrading enzymes) in cell proliferation and neuronal maturation in the hippocampal SGZ of the adult brain during aging.

PPAR $\alpha$ and theirs endogenous ligands such as OEA are involved in the modulation of antioxidant responses, neurotransmission, neuroinflammation, and neurogenesis, which can confer protective roles in models of neurodegenerative and neurocognitive diseases (Heneka et al., 2007; Aleshin and Reiser, 2013; Fidaleo et al., 2014). This nuclear receptor is highly expressed in neuronal populations of certain brain areas such as the hippocampus (Moreno et al., 2004; Rivera et al., 2014), which are particularly implicated in the modulation of learning and memory consolidation. An interesting study aimed at correlating $\operatorname{PPAR} \alpha$ activation and the expression of brain-derived neurotrophic factor (BDNF) in hippocampal neurons demonstrated an improved learning and memory in an animal model of Alzheimer disease via PPAR $\alpha$ (Roy et al., 2015). Overall, PPAR $\alpha$ activation by endogenous (OEA and palmitoylethanolamide) and/or exogenous (fenofibrate) agonists shows a neuroprotective role by increasing brain cell proliferation and improving neuronal survival associated with spatial long-term memory after different cerebral insults such as whole-brain irradiation, cerebral ischemia, and Alzheimer disease (Ramanan et al., 2009; Scuderi et al., 2012; Yang et al., 2015). In this sense, it is appropriate to evaluate whether
PPAR $\alpha$ regulates the NPC proliferation decline throughout adulthood. Interestingly, we demonstrate that PPAR $\alpha$ likely acts as a differential, homeostatic modulator of aging-induced cell proliferation decline in the principal neurogenic niches of the adult brain. As we have found differences in the rate of NPC proliferation in the SVZ of the older mice lacking PPAR $\alpha$ (18 months old), in contrast with the younger mice ( 2 months), the participation of this receptor in neurogenesis may be directly related to aging. Further studies will be needed to assess the protective role of PPAR $\alpha$ associated with improved neurogenesis and better memory performance among the elderly.

Environmental factors can provide profound influences on brain development and functioning during lifespan. It is welldocumented the beneficial effects of enriching environments with physical, social and sensory stimuli on neurogenesis, neuronal sprouting, learning, and memory, suggesting an important therapeutic approach in the prevention and/or recovery of neurodegenerative diseases (Mohammed et al., 2002; Kuzumaki et al., 2011; Garthe et al., 2016). Enriched inputs are able to modulate brain plasticity during all stages of life as a consequence of a variety of responses triggered by neurotrophic and neurogenic factors (Pérez-Martín et al., 2005; García-Segura et al., 2007; Arevalo et al., 2015). Regarding the influence of the environment in the old age, a recent study demonstrated that an enriched environment counteracted the decrease of BDNF levels in the hippocampus of molarless mice, which was in turn associated with the amelioration of proliferation, survival and differentiation of newborn cells in the SGZ and the improvement of hippocampus-dependent spatial memory (Kondo et al., 2015). A previous study indicated that the growth hormone may provide a protective role in old animals as its administration ameliorated neuronal loss associated with aging (Azcoitia et al., 2005). In agreement with this study, chronic IGF-1 treatment reduced spatial learning impairment and upregulated neural proliferation in the SGZ of aged female rats exposed to prenatal stress (Darnaudéry et al., 2006). To go further into the hypothesis, we evaluated the beneficial effects of an enriched environment involving different sets of objects and games (ramps, floor platforms, tunnels and toys) accompanied by nutritional enrichment (fruits, crackers and cheese) for 20 days in old aged mice lacking $\operatorname{PPAR} \alpha$ that showed impaired effects on NPC proliferation. In agreement with this premise, our results indicated that the enriched environment counteracted the $\operatorname{PPAR} \alpha$ deficiency-induced reduction of cell proliferation in the SGZ and the hypothalamus of older mice. Surprisingly, PPAR $\alpha$ deficiency increased cell proliferation in the SVZ of the older mice. These results should be interpreted regarding a specific vulnerability of $\mathrm{Ppar}^{-/-}$mice associated with senescence and deficiency of PPAR $\alpha$-mediated neuroprotection. Both facts probably resulted in a poor survival of new neurons in those brain regions, such as olfactory bulb and striatum, which are tangentially and radially targeted by the NPC of the SVZ. Thus, it is consistent that vulnerability associated with old age and PPAR $\alpha$ deficiency could be the major inducer of striatal neurogenesis. Previous studies established that inflammation accompanying an ischemic insult triggers a marked increase of NPC in the SVZ and leads to the recruitment of formed neuroblasts to 
repair the damaged striatum (Arvidsson et al., 2002; Thored et al., 2006; Chapman et al., 2015; Lin et al., 2015). Our data evidenced that Ppara $^{-/-}$mice housed in enriched environment for 20 days showed a partial recovery toward the basal rate of NPC proliferation that characterizes the SVZ of the older wild-type mice. The enriched environment including contextual stimulation (objects and games) and nutritional treats likely contributes to neuroprotection, which can, in turn, enhance survival of the new-born neurons and, as a consequence, the restoration of the NPC proliferative rate to control levels in the SVZ. We hypothesize that this process is closely regulated by neurotrophic factors (e.g., IGF-1 and estradiol; García-Segura et al., 2007; Arevalo et al., 2015). Future studies will be designed to elucidate the regulation of the main neurotrophic factors (BDNF, IGF-1, estradiol) by PPAR $\alpha$ activation along the elderly.

It should be highlighted the discrepancies of the effects of the enriched environment on NPC proliferation in the SVZ, SGZ, and hypothalamus of the Ppara ${ }^{-/-}$mice. A similar discrepancy regarding the different neurogenic zone of the adult rodent brain was also described in previous studies when neurogenesis was evaluated after different insults such as the exposure to cocaine, alcohol, or a very high fat diet (Rivera et al., 2011, 2015a,b; Blanco-Calvo et al., 2014). In previous studies, we described that adult male rats with a prolonged intake of a high fat diet and treated with the CB1 receptor antagonist AM251 or mice with a repeated administration of cocaine and treated with the $\mathrm{CB} 1$ and $\mathrm{CB} 2$ receptor antagonists Rimonabant and AM630, respectively, showed an increased neural proliferation in the SGZ, but a decreased neural proliferation in the SVZ (Rivera et al., 2011; Blanco-Calvo et al., 2014). In two recent studies from our group, we described that the reduction of neural proliferation in the SVZ and SGZ after the inhibition of the fatty acid amide hydrolase (FAAH) by the repeated administration of URB597, and the increase of neural proliferation in the SVZ and SGZ after CB2 receptor stimulation in alcohol-exposed rats were not observed in the hypothalamus (Rivera et al., 2015a,b).

As a conclusion, the present study indicates that PPAR $\alpha$ deficiency differentially alters the age-induced decline of NPC proliferation in relevant neurogenic niches (SVZ, SGZ, and hypothalamus) of the adult mouse brain. These data suggest a potential modulatory role for $\operatorname{PPAR} \alpha$ in the age-induced neurogenesis decline. This modulation is brain area dependent. While, in the SVZ, the absence of PPAR $\alpha$ promotes more proliferation at older ages, in the SGZ the absence of this

\section{REFERENCES}

Aizawa, K., Ageyama, N., Yokoyama, C., and Hisatsune, T. (2009). Age-dependent alteration in hippocampal neurogenesis correlates with learning performance of macaque monkeys. Exp. Anim. 58, 403-407. doi: 10.1538/expanim.58.403

Albayram, O., Alferink, J., Pitsch, J., Piyanova, A., Neitzert, K., Poppensieker, K., et al. (2011). Role of CB1 cannabinoid receptors on GABAergic neurons in brain aging. Proc. Natl. Acad. Sci. U.S.A. 108, 11256-11261. doi: 10.1073/pnas.1016442108

Aleshin, S., and Reiser, G. (2013). Role of the peroxisome proliferator-activated receptors (PPAR)-alpha, beta/delta and gamma triad in regulation of reactive receptor may lead to maintain a deficiency in neurogenesis. These results suggest that $\operatorname{PPAR} \alpha$ in the SVZ likely acts as a neuroprotective factor. The exposition to nutritional and environmental enrichments of the older mice (18 months old) reversed the $P_{p a r \alpha}{ }^{-/-}$-induced impairment of NPC proliferation in the three neurogenic zones analyzed, but no change was found in hippocampal neuronal maturation. In the SVZ the enhanced cell proliferation is not further potentiated by environmental enrichment, whereas EE boosts cell proliferation in the SGZ and hypothalamus of the $\mathrm{Ppar \alpha}^{-/}$animal. Further studies with PPAR $\alpha$ activators such as OEA are needed to investigate whether this role can be of therapeutic value for behavioral impairment associated with aging.

\section{AUTHOR CONTRIBUTIONS}

All authors had full access to all data in the study and take responsibility for the integrity of the data and the accuracy of the data analyses. Study concept and design: MP, PR, EB, FR, and JS. Acquisition of data: PR, EB, CL, and JD. Analysis and interpretation of data: MP, PR, EB, FR, and JS. Drafting of the manuscript: MP, FR, and JS. Critical revision of the manuscript for important intellectual content, obtained funding and study supervision: FP, AS, FR, and JS.

\section{ACKNOWLEDGMENTS}

Grant sponsor: 7th Framework Programme of European Union. Grant number: HEALTH-F2-2008-223713, REPROBESITY to FR. Grant sponsor: Instituto de Salud Carlos III (ISCIII), Ministerio de Economía y Competitividad (MINECO), UEERDF. Grant numbers: PI13/02261 to FR. and CP12/03109 to JS. Grant sponsor: Red de Trastornos Adictivos, ISCIII, MINECO. Grant number: RD12/0028/0001 to FR. Grant sponsor: Plan Nacional Sobre Drogas, Ministerio de Sanidad y Consumo. Grant number: PNSD2010/143 and PNSD2015/047 to JS. Grant sponsor: Fundació La Marató de TV3. Grant number: 386/C/2011. Grant sponsor: Consejería de Economía, Innovación y Ciencia, Junta de Andalucía, UE/ERDF. Grant numbers: PI45403 and CTS-8221 to FR. Grant sponsor: Consejería de Salud, Junta de Andalucía, UE/ERDF. Grant number: SAS111224 to FR. JS, FP and AS hold "Miguel Servet" research contracts from the National System of Health, ISCIII (grant numbers: CP12/03109, CP14/00212 and CP14/00173, respectively). oxygen species signaling in brain. Biol. Chem. 394, 1553-1570. doi: 10.1515/hsz2013-0215

Alvarez-Buylla, A., and Lim, D. A. (2004). For the long run: maintaining germinal niches in the adult brain. Neuron 41, 683-686. doi: 10.1016/S08966273(04)00111-4

Arevalo, M. A., Azcoitia, I., Gonzalez-Burgos, I., and Garcia-Segura, L. M. (2015). Signaling mechanisms mediating the regulation of synaptic plasticity and memory by estradiol. Horm. Behav. 74, 19-27. doi: 10.1016/j.yhbeh. 2015.04.016

Arias-Carrion, O., Olivares-Bunuelos, T., and Drucker-Colin, R. (2007). [Neurogenesis in the adult brain]. Rev. Neurol. 44, 541-550. 
Arvidsson, A., Collin, T., Kirik, D., Kokaia, Z., and Lindvall, O. (2002). Neuronal replacement from endogenous precursors in the adult brain after stroke. Nat. Med. 8, 963-970. doi: 10.1038/nm747

Avshalumov, M. V., and Rice, M. E. (2002). NMDA receptor activation mediates hydrogen peroxide-induced pathophysiology in rat hippocampal slices. J. Neurophysiol. 87, 2896-2903. doi: 10.1152/jn.01011.2001

Azcoitia, I., Perez-Martin, M., Salazar, V., Castillo, C., Ariznavarreta, C., Garcia-Segura, L. M., et al. (2005). Growth hormone prevents neuronal loss in the aged rat hippocampus. Neurobiol. Aging 26, 697-703. doi: 10.1016/j.neurobiolaging.2004.06.007

Bento-Abreu, A., Tabernero, A., and Medina, J. M. (2007). Peroxisome proliferator-activated receptor-alpha is required for the neurotrophic effect of oleic acid in neurons. J. Neurochem. 103, 871-881. doi: 10.1111/j.14714159.2007.04807.x

Bilbao, A., Serrano, A., Cippitelli, A., Pavón, F. J., Giuffrida, A., Suárez, J., et al. (2015). Role of the satiety factor oleoylethanolamide in alcoholism. Addict. Biol. doi: 10.1111/adb.12276. [Epub ahead of print].

Bizon, J. L., and Gallagher, M. (2003). Production of new cells in the rat dentate gyrus over the lifespan: relation to cognitive decline. Eur. J. Neurosci. 18, 215-219. doi: 10.1046/j.1460-9568.2003.02733.x

Blanco-Calvo, E., Rivera, P., Arrabal, S., Vargas, A., Pavón, F. J., Serrano, A., et al. (2014). Pharmacological blockade of either cannabinoid CB1 or CB2 receptors prevents both cocaine-induced conditioned locomotion and cocaine-induced reduction of cell proliferation in the hippocampus of adult male rat. Front. Integr. Neurosci. 7:106. doi: 10.3389/fnint.2013.00106

Campolongo, P., Roozendaal, B., Trezza, V., Cuomo, V., Astarita, G., Fu, J., et al. (2009). Fat-induced satiety factor oleoylethanolamide enhances memory consolidation. Proc. Natl. Acad. Sci. U.S.A. 106, 8027-8031. doi: 10.1073/pnas.0903038106

Chapman, K. Z., Ge, R., Monni, E., Tatarishvili, J., Ahlenius, H., Arvidsson, A., et al. (2015). Inflammation without neuronal death triggers striatal neurogenesis comparable to stroke. Neurobiol. Dis. 83, 1-15. doi: 10.1016/j.nbd.2015.08.013

Cimini, A., and Ceru, M. P. (2008). Emerging roles of peroxisome proliferatoractivated receptors (PPARs) in the regulation of neural stem cells proliferation and differentiation. Stem Cell Rev. 4, 293-303. doi: 10.1007/s12015-008-9024-2

Cimini, A., Cristiano, L., Benedetti, E., D’Angelo, B., and Ceru, M. P. (2007). PPARs expression in adult mouse neural stem cells: modulation of PPARs during astroglial differentiaton of NSC. PPAR Res. 2007:48242. doi: $10.1155 / 2007 / 48242$

Coras, R., Siebzehnrubl, F. A., Pauli, E., Huttner, H. B., Njunting, M., Kobow, K., et al. (2010). Low proliferation and differentiation capacities of adult hippocampal stem cells correlate with memory dysfunction in humans. Brain 133, 3359-3372. doi: 10.1093/brain/awq215

Cristiano, L., Cimini, A., Moreno, S., Ragnelli, A. M., and Paola Ceru, M. (2005). Peroxisome proliferator-activated receptors (PPARs) and related transcription factors in differentiating astrocyte cultures. Neuroscience 131, 577-587. doi: 10.1016/j.neuroscience.2004.11.008

Darnaudéry, M., Perez-Martin, M., Bélizaire, G., Maccari, S., and Garcia-Segura, L. M. (2006). Insulin-like growth factor 1 reduces age-related disorders induced by prenatal stress in female rats. Neurobiol. Aging 27, 119-127. doi: 10.1016/j.neurobiolaging.2005.01.008

Doetsch, F. (2003a). The glial identity of neural stem cells. Nat. Neurosci. 6, 1127-1134. doi: 10.1038/nn1144

Doetsch, F. (2003b). A niche for adult neural stem cells. Curr. Opin. Genet. Dev. 13, 543-550. doi: 10.1016/j.gde.2003.08.012

Doetsch, F., Garcia-Verdugo, J. M., and Alvarez-Buylla, A. (1999). Regeneration of a germinal layer in the adult mammalian brain. Proc. Natl. Acad. Sci. U.S.A. 96, 11619-11624. doi: 10.1073/pnas.96.20.11619

Drapeau, E., Mayo, W., Aurousseau, C., Le Moal, M., Piazza, P. V., and Abrous, D. N. (2003). Spatial memory performances of aged rats in the water maze predict levels of hippocampal neurogenesis. Proc. Natl. Acad. Sci. U.S.A. 100, 14385-14390. doi: 10.1073/pnas.2334169100

Fan, Y., Liu, Z., Weinstein, P. R., Fike, J. R., and Liu, J. (2007). Environmental enrichment enhances neurogenesis and improves functional outcome after cranial irradiation. Eur. J. Neurosci. 25, 38-46. doi: 10.1111/j.1460-9568.2006.05269.x

Fandel, D., Wasmuht, D., Avila-Martin, G., Taylor, J. S., Galan-Arriero, I., and Mey, J. (2013). Spinal cord injury induced changes of nuclear receptors PPARalpha and LXRbeta and modulation with oleic acid/albumin treatment. Brain Res. 1535, 89-105. doi: 10.1016/j.brainres.2013.08.022

Fidaleo, M., Fanelli, F., Ceru, M. P., and Moreno, S. (2014). Neuroprotective properties of peroxisome proliferator-activated receptor alpha (PPARalpha) and its lipid ligands. Curr. Med. Chem. 21, 2803-2821. doi: 10.2174/0929867321666140303143455

García-Segura, L. M., Diz-Chaves, Y., Perez-Martin, M., and Darnaudéry, M. (2007). Estradiol, insulin-like growth factor-I and brain aging. Psychoneuroendocrinology 32(Suppl. 1), S57-S61. doi: 10.1016/j.psyneuen.2007.03.001

Garthe, A., Roeder, I., and Kempermann, G. (2016). Mice in an enriched environment learn more flexibly because of adult hippocampal neurogenesis. Hippocampus 26, 261-271. doi: 10.1002/hipo.22520

González-Aparicio, R., Blanco, E., Serrano, A., Pavon, F. J., Parsons, L. H., Maldonado, R., et al. (2014). The systemic administration of oleoylethanolamide exerts neuroprotection of the nigrostriatal system in experimental Parkinsonism. Int. J. Neuropsychopharmacol. 17, 455-468. doi: 10.1017/S1461145713001259

Hajjar, T., Meng, G. Y., Rajion, M. A., Vidyadaran, S., Othman, F., Farjam, A. S., et al. (2012). Omega 3 polyunsaturated fatty acid improves spatial learning and hippocampal peroxisome proliferator activated receptors (PPARalpha and PPARgamma) gene expression in rats. BMC Neurosci. 13:109. doi: 10.1186/1471-2202-13-109

Heneka, M. T., Landreth, G. E., and Hull, M. (2007). Drug insight: effects mediated by peroxisome proliferator-activated receptor-gamma in CNS disorders. Nat. Clin. Pract. Neurol. 3, 496-504. doi: 10.1038/ncpneuro0586

Kondo, H., Kurahashi, M., Mori, D., Iinuma, M., Tamura, Y., Mizutani, K., et al. (2015). Hippocampus-dependent spatial memory impairment due to molar tooth loss is ameliorated by an enriched environment. Arch. Oral Biol. 61, 1-7. doi: 10.1016/j.archoralbio.2015.10.006

Kuhn, H. G., Dickinson-Anson, H., and Gage, F. H. (1996). Neurogenesis in the dentate gyrus of the adult rat: age-related decrease of neuronal progenitor proliferation. J. Neurosci. 16, 2027-2033.

Kuzumaki, N., Ikegami, D., Tamura, R., Hareyama, N., Imai, S., Narita, M., et al. (2011). Hippocampal epigenetic modification at the brain-derived neurotrophic factor gene induced by an enriched environment. Hippocampus 21, 127-132. doi: 10.1002/hipo.20775

Lie, D. C., Song, H., Colamarino, S. A., Ming, G. L., and Gage, F. H. (2004). Neurogenesis in the adult brain: new strategies for central nervous system diseases. Annu. Rev. Pharmacol. Toxicol. 44, 399-421. doi: 10.1146/annurev.pharmtox.44.101802.121631

Lin, R., Cai, J., Nathan, C., Wei, X., Schleidt, S., Rosenwasser, R., et al. (2015). Neurogenesis is enhanced by stroke in multiple new stem cell niches along the ventricular system at sites of high BBB permeability. Neurobiol. Dis. 74, 229-239. doi: 10.1016/j.nbd.2014.11.016

Lin, R., and Iacovitti, L. (2015). Classic and novel stem cell niches in brain homeostasis and repair. Brain Res. 1628(Pt B), 327-342. doi: 10.1016/j.brainres.2015.04.029

Maggi, R., Zasso, J., and Conti, L. (2014). Neurodevelopmental origin and adult neurogenesis of the neuroendocrine hypothalamus. Front. Cell. Neurosci. 8:440. doi: $10.3389 /$ fncel.2014.00440

McDonald, H. Y., and Wojtowicz, J. M. (2005). Dynamics of neurogenesis in the dentate gyrus of adult rats. Neurosci. Lett. 385, 70-75. doi: 10.1016/j.neulet.2005.05.022

Melis, M., Carta, G., Pistis, M., and Banni, S. (2013). Physiological role of peroxisome proliferator-activated receptors type alpha on dopamine systems. CNS Neurol. Disord. Drug Targets 12, 70-77. doi: $10.2174 / 1871527311312010012$

Merrill, D. A., Karim, R., Darraq, M., Chiba, A. A., and Tuszynski, M. H. (2003). Hippocampal cell genesis does not correlate with spatial learning ability in aged rats. J. Comp. Neurol. 459, 201-207. doi: 10.1002/cne. 10616

Mohammed, A. H., Zhu, S. W., Darmopil, S., Hjerling-Leffler, J., Ernfors, P., Winblad, B., et al. (2002). Environmental enrichment and the brain. Prog. Brain Res. 138, 109-133. doi: 10.1016/S0079-6123(02)38074-9

Montalban-Loro, R., Domingo-Muelas, A., Bizy, A., and Ferron, S. R. (2015). Epigenetic regulation of stemness maintenance in the neurogenic niches. World J. Stem Cells 7, 700-710. doi: 10.4252/wjsc.v7.i4.700 
Moreno, S., Farioli-Vecchioli, S., and Ceru, M. P. (2004). Immunolocalization of peroxisome proliferator-activated receptors and retinoid $\mathrm{X}$ receptors in the adult rat CNS. Neuroscience 123, 131-145. doi: 10.1016/j.neuroscience.2003.08.064

Ngwenya, L. B., Heyworth, N. C., Shwe, Y., Moore, T. L., and Rosene, D. L. (2015). Age-related changes in dentate gyrus cell numbers, neurogenesis, and associations with cognitive impairments in the rhesus monkey. Front. Syst. Neurosci. 9:102. doi: 10.3389/fnsys.2015.00102

Nunomura, A., Moreira, P. I., Castellani, R. J., Lee, H. G., Zhu, X., Smith, M. A., et al. (2012). Oxidative damage to RNA in aging and neurodegenerative disorders. Neurotoxicol. Res. 22, 231-248. doi: 10.1007/s12640-012-9331-x

Paillard, T. (2015). Preventive effects of regular physical exercise against cognitive decline and the risk of dementia with age advancement. Sports Med. Open 1:4. doi: 10.1186/s40798-015-0016-x

Paxinos, G., and Franklin, K. B. J. (2004). The Mouse Brain in Stereotaxic Coordinates, Compact, 2nd Edn. Boston, MA: Elsevier Academic Press.

Pérez-Martín, M., Salazar, V., Castillo, C., Ariznavarreta, C., Azcoitia, I., GarciaSegura, L. M., et al. (2005). Estradiol and soy extract increase the production of new cells in the dentate gyrus of old rats. Exp. Gerontol. 40, 450-453. doi: 10.1016/j.exger.2005.03.003

Plaza-Zabala, A., Berrendero, F., Suarez, J., Bermudez-Silva, F. J., FernandezEspejo, E., Serrano, A., et al. (2010). Effects of the endogenous PPAR-alpha agonist, oleoylethanolamide on MDMA-induced cognitive deficits in mice. Synapse 64, 379-389. doi: 10.1002/syn.20733

Ramanan, S., Kooshki, M., Zhao, W., Hsu, F. C., Riddle, D. R., and Robbins, M. E. (2009). The PPARalpha agonist fenofibrate preserves hippocampal neurogenesis and inhibits microglial activation after whole-brain irradiation. Int. J. Radiat. Oncol. Biol. Phys. 75, 870-877. doi: 10.1016/j.ijrobp.2009.06.059

Rivera, P., Arrabal, S., Vargas, A., Blanco, E., Serrano, A., Pavon, F. J., et al. (2014). Localization of peroxisome proliferator-activated receptor alpha (PPARalpha) and N-acyl phosphatidylethanolamine phospholipase D (NAPE$\mathrm{PLD}$ ) in cells expressing the $\mathrm{Ca}(2+)$-binding proteins calbindin, calretinin, and parvalbumin in the adult rat hippocampus. Front. Neuroanat. 8:12. doi: 10.3389/fnana.2014.00012

Rivera, P., Bindila, L., Pastor, A., Perez-Martin, M., Pavon, F. J., Serrano, A., et al. (2015a). Pharmacological blockade of the fatty acid amide hydrolase (FAAH) alters neural proliferation, apoptosis and gliosis in the rat hippocampus, hypothalamus and striatum in a negative energy context. Front. Cell. Neurosci. 9:98. doi: 10.3389/fncel.2015.00098

Rivera, P., Blanco, E., Bindila, L., Alen, F., Vargas, A., Rubio, L., et al. (2015b). Pharmacological activation of $\mathrm{CB} 2$ receptors counteracts the deleterious effect of ethanol on cell proliferation in the main neurogenic zones of the adult rat brain. Front. Cell. Neurosci. 9:379. doi: 10.3389/fncel.2015.00379

Rivera, P., Romero-Zerbo, Y., Pavon, F. J., Serrano, A., Lopez-Avalos, M. D., Cifuentes, M., et al. (2011). Obesity-dependent cannabinoid modulation of proliferation in adult neurogenic regions. Eur. J. Neurosci. 33, 1577-1586. doi: 10.1111/j.1460-9568.2011.07650.x

Roberts, R. A., Chevalier, S., Hasmall, S. C., James, N. H., Cosulich, S. C., and Macdonald, N. (2002). PPAR alpha and the regulation of cell division and apoptosis. Toxicology 181-182,167-170. doi: 10.1016/S0300-483X(02)00275-5

Robins, S. C., Stewart, I., McNay, D. E., Taylor, V., Giachino, C., Goetz, M., et al. (2013). alpha-Tanycytes of the adult hypothalamic third ventricle include distinct populations of FGF-responsive neural progenitors. Nat. Commun. 4:2049. doi: $10.1038 /$ ncomms 3049
Romano, A., Cassano, T., Tempesta, B., Cianci, S., Dipasquale, P., Coccurello, R., et al. (2013). The satiety signal oleoylethanolamide stimulates oxytocin neurosecretion from rat hypothalamic neurons. Peptides 49, 21-26. doi: 10.1016/j.peptides.2013.08.006

Rosen, E. D., and Spiegelman, B. M. (2001). PPARgamma: a nuclear regulator of metabolism, differentiation, and cell growth. J. Biol. Chem. 276, 37731-37734. doi: 10.1074/jbc.R100034200

Roy, A., Jana, M., Kundu, M., Corbett, G. T., Rangaswamy, S. B., Mishra, R. K., et al. (2015). HMG-CoA reductase inhibitors bind to PPARalpha to upregulate neurotrophin expression in the brain and improve memory in mice. Cell Metab. 22, 253-265. doi: 10.1016/j.cmet.2015.05.022

Scuderi, C., Valenza, M., Stecca, C., Esposito, G., Carratu, M. R., and Steardo, L. (2012). Palmitoylethanolamide exerts neuroprotective effects in mixed neuroglial cultures and organotypic hippocampal slices via peroxisome proliferator-activated receptor-alpha. J. Neuroinflammation 9:49. doi: 10.1186/1742-2094-9-21

Smith, S. A., Monteith, G. R., Holman, N. A., Robinson, J. A., May, F. J., and Roberts-Thomson, S. J. (2003). Effects of peroxisome proliferator-activated receptor gamma ligands ciglitazone and 15-deoxy-delta 12,14-prostaglandin J2 on rat cultured cerebellar granule neuronal viability. J. Neurosci. Res. 72, 747-755. doi: 10.1002/jnr.10613

Thored, P., Arvidsson, A., Cacci, E., Ahlenius, H., Kallur, T., Darsalia, V., et al. (2006). Persistent production of neurons from adult brain stem cells during recovery after stroke. Stem Cells 24, 739-747. doi: 10.1634/stemcells.2005-0281

Van Praag, H., Shubert, T., Zhao, C., and Gage, F. H. (2005). Exercise enhances learning and hippocampal neurogenesis in aged mice. J. Neurosci. 25, 8680-8685. doi: 10.1523/JNEUROSCI.1731-05.2005

Yang, L. C., Guo, H., Zhou, H., Suo, D. Q., Li, W. J., Zhou, Y., et al. (2015). Chronic oleoylethanolamide treatment improves spatial cognitive deficits through enhancing hippocampal neurogenesis after transient focal cerebral ischemia. Biochem. Pharmacol. 94, 270-281. doi: 10.1016/j.bcp.2015.02.012

Zhao, Y., Chen, K., and Shen, X. (2015). Environmental Enrichment Attenuated Sevoflurane-Induced Neurotoxicity through the PPAR-gamma Signaling Pathway. Biomed Res. Int. 2015:107149. doi: 10.1155/2015/107149

Zhou, Y. C., and Waxman, D. J. (1998). Activation of peroxisome proliferatoractivated receptors by chlorinated hydrocarbons and endogenous steroids. Environ. Health Perspect. 106(Suppl. 4), 983-988.

Zolezzi, J. M., Silva-Alvarez, C., Ordenes, D., Godoy, J. A., Carvajal, F. J., Santos, M. J., et al. (2013). Peroxisome proliferator-activated receptor (PPAR) gamma and PPARalpha agonists modulate mitochondrial fusion-fission dynamics: relevance to reactive oxygen species (ROS)-related neurodegenerative disorders? PLoS ONE 8:e64019. doi: 10.1371/journal.pone.0064019

Conflict of Interest Statement: The authors declare that the research was conducted in the absence of any commercial or financial relationships that could be construed as a potential conflict of interest.

Copyright (C) 2016 Pérez-Martín, Rivera, Blanco, Lorefice, Decara, Pavón, Serrano, Rodríguez de Fonseca and Suárez. This is an open-access article distributed under the terms of the Creative Commons Attribution License (CC BY). The use, distribution or reproduction in other forums is permitted, provided the original author(s) or licensor are credited and that the original publication in this journal is cited, in accordance with accepted academic practice. No use, distribution or reproduction is permitted which does not comply with these terms. 